\title{
Effects of Cable Flexural Rigidity on the Free Vibrations of Suspension Bridges
}

\author{
Tatjana GRIGORJEVA ${ }^{1, a^{*}}$, Zenonas KAMAITIS K,b $^{2, b}$ \\ ${ }^{1,2}$ Sauletekio al. 11, LT-10223 Vilnius, Lithuania \\ atatjana.grigorjeva@vgtu.It, 'benonas.kamaitis@vgtu.It \\ ${ }^{*}$ Corresponding author
}

Keywords: Suspension Bridges, Cable Bending Stiffness, Free Vibrations, Fe Analysis.

\begin{abstract}
The natural frequencies of vibration and the corresponding mode shapes of a suspension bridge with varying bending stiffness of cables are determined, and the changes that occur in these characteristics with respect to parametric changes in the bridge are examined. Single span $L=64,0 \mathrm{~m}$ suspension steel footbridge with hangers and flexible cables is selected as an initial model used to study the dynamic characteristics of a suspension system. Based on FEA parameter studies are presented in which the vibration characteristics are studied as a function of structural and material parameters, such as cable flexural stiffness, modulus of elasticity and mass density of structural components. It is generally found that the main cable bending stiffness contributes a considerable effect on the natural frequencies of the suspension system.
\end{abstract}

\section{Introduction}

The suspension bridges are inherently the flexible structures and in the majority of cases special measures of stiffening must be incorporated in the design. Some suspension bridges have in the past suffered from structural failure [e.g. 1, 2]. It is well known that the suspension footbridges that are long, light and slender structures are particularly susceptible to large vibrations induced by pedestrians and wind actions leading sometimes to serviceability and safety problems $[3,4,5]$. The structural measures commonly adopted to reduce vibrations of bridges consist of local or total structural modifications by changing mainly the stiffness or the mass of a structure as well as through the installation of tuned mass dampers. As is shown in our previous investigations a possible strategy for modification of structural stiffness of a suspension system is the variation of main cable stiffness [6]. By changing of the cable to stiffening girder bending stiffness ratio it is possible to reduce considerably the vertical displacements of the loaded suspension system and to retain its original geometric form. The stabilization of the deformability of the suspension bridges by giving certain bending stiffness to the suspension cables are also known in practice. The famous London Tower Bridge can be mentioned. It should be mentioned also that in the long-span suspension bridges the rigidity of main cables becomes dominant with respect to that of the deck [7]. So far as the authors' know, the investigation on the suspension bridge dynamic response taken into consideration bending stiffness of cables until now was not carried out. This paper treats the free vibration response of suspension steel footbridge with varying flexural rigidity of main cables using FE method.

\section{Footbridge Description FE Model}

The effect of main cable bending stiffness on the free vibration characteristics of a suspension bridge was analysed on an example of the real footbridge designed as a suspension steel structure. The footbridge consists of a single span $64 \mathrm{~m}$ long and $4 \mathrm{~m}$ width superstructure, which includes two main suspension cables, the suspenders and the stiffening deck girder. For computational purposes suspension system was slightly simplified. The suspension bridge model considered in this study is shown in Fig. 1.

The following data were used in the numerical simulation: $\mathrm{L}=64,0 \mathrm{~m}$, cable sag $\mathrm{f}_{0}=6,5 \mathrm{~m}$, width of the deck 4,0 m, Steel suspender rods, of $20 \mathrm{~mm}$ diameter equally spaced every 3,0 m. Flexible cables are of $0,05 \mathrm{~m}$ diameter. The rigidity of flexible cables is $\mathrm{EA}_{\mathrm{c}}=41,2 \times 10^{4} \mathrm{kN}$ and that of stiffening deck 
$\mathrm{EI}_{\mathrm{dx}}=10,7 \mathrm{x} 10^{4} \mathrm{kNm}^{2}$ and $\mathrm{EI}_{\mathrm{dy}}=3870 \mathrm{kNm}^{2}$. For all structural members the basic material is steel with $\mathrm{E}=210 \mathrm{GPa}, \nu=0,3$ and $\gamma=7850 \mathrm{~kg} / \mathrm{m}^{3}$.

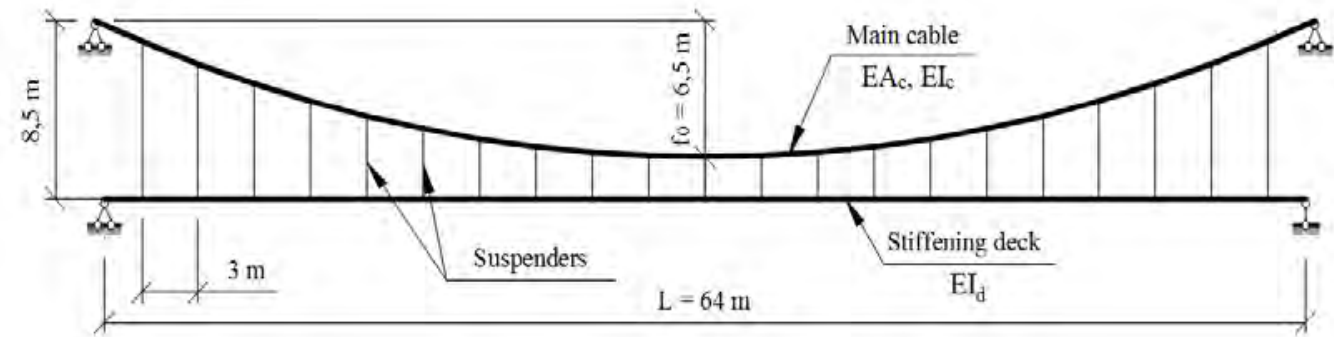

Fig. 1 Single Span Suspension Bridge Model

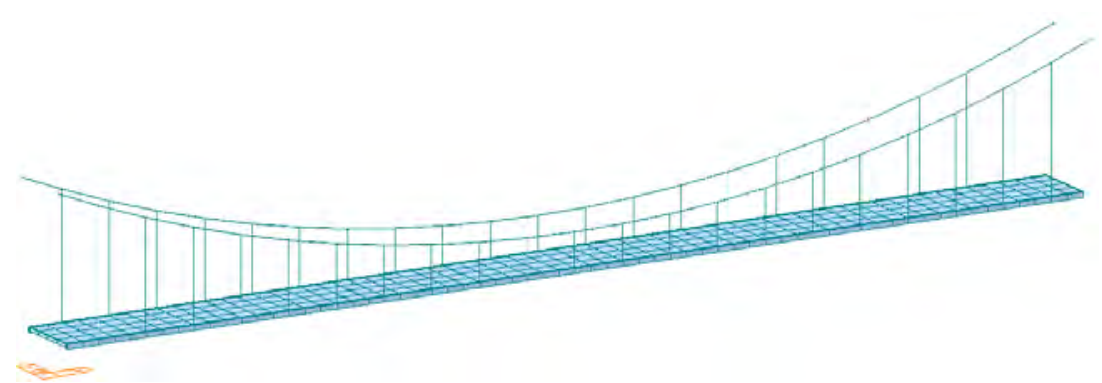

Fig. 2 Finite Element Space Model of the Footbridge

Dynamic analysis of the footbridge was carried out using 3D FE model developed in the program MIDAS Civil, as shown in Fig. 2. The elements TRUSS3D were used to represent the flexible cable and the suspenders. Beam elements BEAM3D were used for the rigid cables and the stiffening girder. The girder deck and the cables are hinged to the tower footings and tower saddles, respectively. The cables are fixed against translation in any direction at the towers.

\section{Modal Parameters of Footbridge with Flexible Cables}

Dynamic analysis of a suspension structure was carried out in terms of natural frequencies and mode shapes which are always very important characteristics for serviceability behavior of the footbridges. It is decided to select 9 modes in the frequency range $0-5 \mathrm{~Hz}$ to be important for pedestrian induced excitations. These include five vertical-dominant, one lateral-dominant and four tension-dominant modes of the deck (Table 1). The fundamental mode is a bending mode with one node. Note, that during numerical simulations the vertical V1 and torsional T1 modes with one half waves were not identified. All torsional modes are coupled with lateral vibrations. The frequency ratio between the 1 st torsional and 1 st vertical modes $(\mathrm{fT} 2 / \mathrm{fV} 2=1,812 / 0,616=2,94)$ suggested that footbridge has relatively high structural torsional stiffness [8].

The mode shapes of two lowest vertical and two torsional modes are shown in Fig. 3.

Tab.1 Computed Eigen-Frequencies and Eigen-Modes

\begin{tabular}{|l|l|l|}
\hline Mode No & Frequency $[\mathrm{Hz}]$ & Character of eigen-mode \\
\hline $1(\mathrm{~V} 2)$ & 0,616 & $2^{\text {nd }}$ vertical \\
$2(\mathrm{~V} 3)$ & 1,128 & $3^{\text {rd }}$ vertical \\
$3(\mathrm{~T} 2-\mathrm{L})$ & 1,812 & $2^{\text {nd }}$ torsional-lateral \\
$4(\mathrm{~V} 4)$ & 2,392 & $4^{\text {th }}$ vertical \\
$5(\mathrm{~L}-\mathrm{T} 3)$ & 2,797 & $3^{\text {rd }}$ lateral-torsional \\
$6(\mathrm{~V} 5)$ & 3,632 & $5^{\text {th }}$ vertical \\
$7(\mathrm{~T} 4-\mathrm{L})$ & 3,668 & $4^{\text {th }}$ torsional-lateral \\
$8(\mathrm{~T} 5-\mathrm{L})$ & 4,744 & $5^{\text {th }}$ torsional-lateral \\
$9(\mathrm{~V} 6)$ & 4,952 & $6^{\text {th }}$ vertical \\
\hline
\end{tabular}




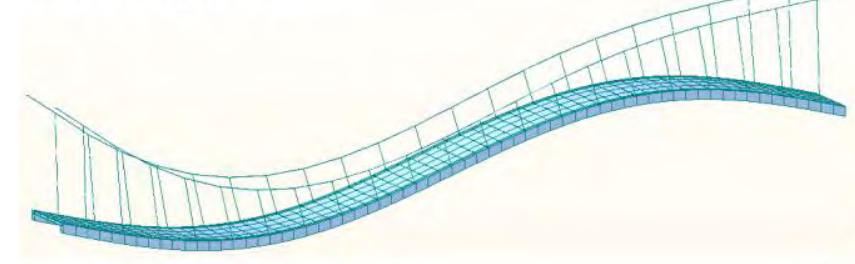

Mode 3: $\mathrm{f}=1,812 \mathrm{~Hz}$
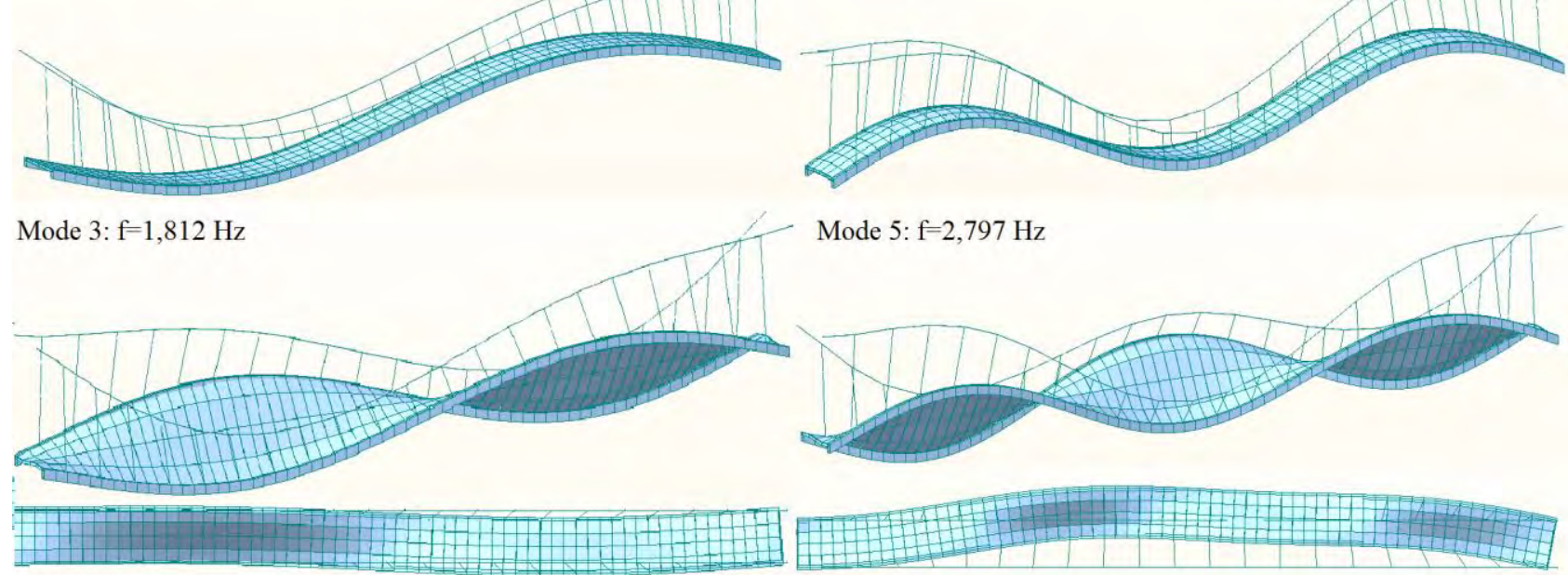

Mode 5 : $\mathrm{f}=2,797 \mathrm{~Hz}$

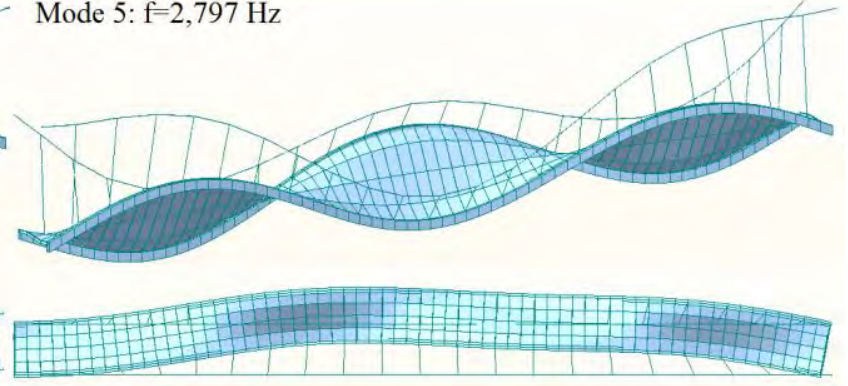

Fig. 3 Mode Shapes of the First Two Vertical and Two Coupled Torsional Modes of the Footbridge

\section{Modal Parameters of Footbridge with Varying Rigidity of Cables}

The effect of cable flexural stiffness on the modal properties of the footbridge is studied by changing the cable to beam bending stiffness ratio $\xi=\mathrm{EI}_{\mathrm{c}} / \mathrm{EI}_{\mathrm{d}}=0,2 ; 0,5 ; 1,0 ; 2,0$ and 5,0 . The main cables are steel tubular members with varying cross-section's diameter. The vertical and lateral bending stiffness of the deck is maintained constant.

Vertical frequencies for all vertical resonant modes for different cable stiffness ratio $\xi$ are presented in Fig 4,a and Table 2. The stiffening effect is clearly observed. The natural frequencies of the footbridge with stiffened cables were up to $60 \%$ higher for asymmetric modes and up to $80 \%$ higher for symmetric modes than those of the footbridge with flexible cables (Table 2).

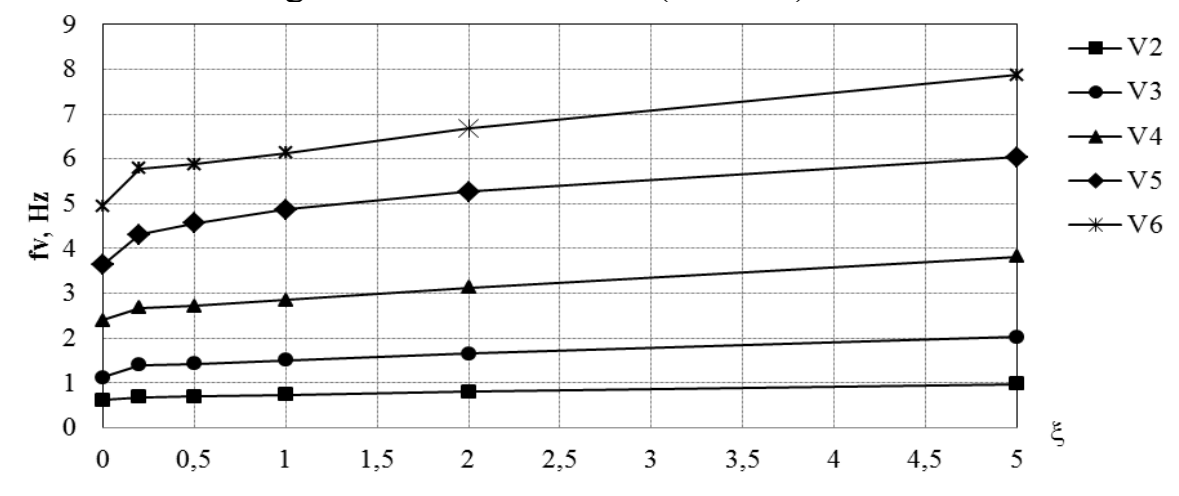

a

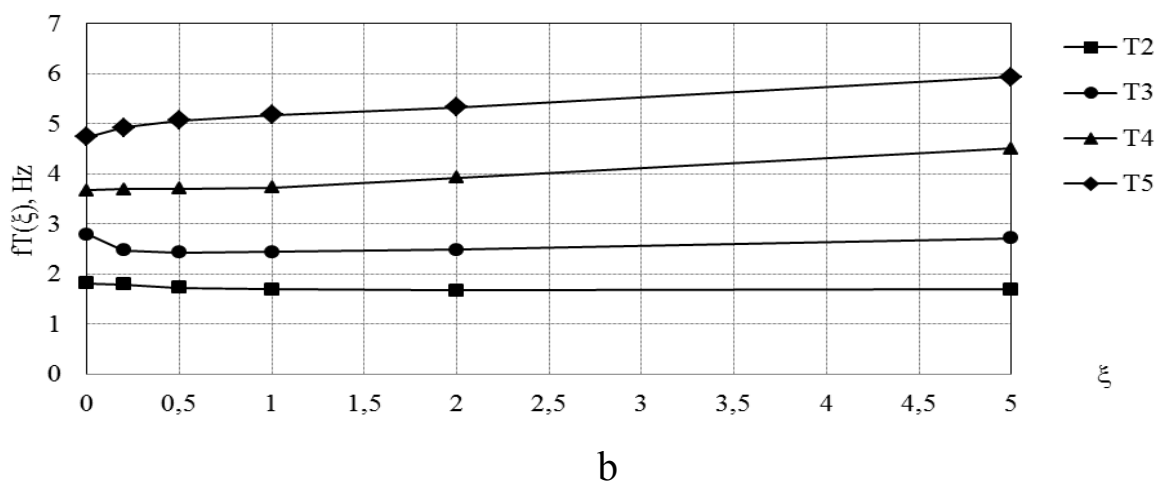

Fig. 4 Effect of the Cable Stiffness Ratio $\xi$ on the Vertical (a) and Torsional (b) Frequencies of Vibration 
It should be noted that a variation of cable stiffness causes to reordering of some modes. The mode V4 and V5 occurred at order 4 an 6 at $\xi=0$, become the fifth and seven, respectively at $\xi=0,2$. Further, the mode V5 changes his position to number 8 at $\xi=2,0$. The second mode V3 being in position 2 becomes mode number 3 only at $\xi=5,0$.

Tab.2 Natural Vibration Frequencies and Frequencies Ratio for the First Four Vertical Modes

\begin{tabular}{|c|c|c|c|c|c|c|c|c|}
\hline$\xi$ & $\mathrm{f}_{\mathrm{V} 2}[\mathrm{~Hz}]$ & $\mathrm{f}_{\mathrm{V} 2} / \mathrm{f}(0)$ & $\mathrm{f}_{\mathrm{V} 3}[\mathrm{~Hz}]$ & $\mathrm{f}_{\mathrm{V} 3} / \mathrm{f}(0)$ & $\mathrm{f}_{\mathrm{V} 4}[\mathrm{~Hz}]$ & $\mathrm{f}_{\mathrm{V} 4} / \mathrm{f}(0)$ & $\mathrm{f}_{\mathrm{V} 5}[\mathrm{~Hz}]$ & $\mathrm{f}_{\mathrm{V} 5} / \mathrm{f}(0)$ \\
\hline 0 & 0,616 & 1,0 & 1,128 & 1,0 & 2,392 & 1,0 & 3,632 & 1,0 \\
\hline 0,2 & 0,683 & 1,11 & 1,404 & 1,25 & 2,672 & 1,12 & 4,613 & 1,27 \\
\hline 0,5 & 0,695 & 1,13 & 1,433 & 1,27 & 2,720 & 1,14 & 4,685 & 1,29 \\
\hline 1,0 & 0,730 & 1,18 & 1,503 & 1,33 & 2,851 & 1,19 & 4,903 & 1,35 \\
\hline 2,0 & 0,801 & 1,30 & 1,652 & 1,47 & 3,131 & 1,31 & 5,412 & 1,49 \\
\hline 5,0 & 0,982 & 1,60 & 2,031 & 1,80 & 3,824 & 1,60 & 6,538 & 1,80 \\
\hline
\end{tabular}

Tab.3 Natural Vibration Frequencies and Frequencies Ratio for the First Four Torsional Modes

\begin{tabular}{|c|c|c|c|c|c|c|c|c|}
\hline$\xi$ & $\mathrm{f}_{\mathrm{T} 2}[\mathrm{~Hz}]$ & $\mathrm{f}_{\mathrm{T} 2} / \mathrm{f}(0)$ & $\mathrm{f}_{\mathrm{T} 3}[\mathrm{~Hz}]$ & $\mathrm{f}_{\mathrm{T} 3} / \mathrm{f}(0)$ & $\mathrm{f}_{\mathrm{T} 4}[\mathrm{~Hz}]$ & $\mathrm{f}_{\mathrm{T} 4} / \mathrm{f}(0)$ & $\mathrm{f}_{\mathrm{T} 5}[\mathrm{~Hz}]$ & $\mathrm{f}_{\mathrm{T} 5} / \mathrm{f}(0)$ \\
\hline 0 & 1,812 & 1,0 & 2,797 & 1,0 & 3,668 & 1,0 & 4,744 & 1,0 \\
\hline 0,2 & 1,789 & 0,99 & 2,473 & 0,88 & 3,697 & 1,01 & 4,928 & 1,04 \\
\hline 0,5 & 1,730 & 0,95 & 2,436 & 0,87 & 3,702 & 1,01 & 5,066 & 1,07 \\
\hline 1,0 & 1,690 & 0,93 & 2,443 & 0,87 & 3,728 & 1,02 & 5,175 & 1,09 \\
\hline 2,0 & 1,669 & 0,92 & 2,486 & 0,89 & 3,928 & 1,07 & 5,334 & 1,12 \\
\hline 5,0 & 1,697 & 0,94 & 2,545 & 0,91 & 4,509 & 1,23 & 5,934 & 1,25 \\
\hline
\end{tabular}

Torsional frequencies for all torsional resonant modes for different ratio $\xi$ are presented in Fig. 4,b and Table 3. It is evident that cable stiffness has different effect on the torsional resonant modes. The stiffened cables increase by about $25 \%$ only the frequencies of the higher modes (T4 and T5). The first two lower mode frequencies slightly decrease when the cable stiffness increases and the rate of decrease is the largest for the $1^{\text {st }}$ mode T2 (Table 3 ). This is, probably, due to increasing the eccentric mass of the cables $[8,9]$ and reordering of all torsional modes. Torsional and vertical modes change positions between, leading to decrease the values of torsional mode frequencies. The frequency ratio between the $1^{\text {st }}$ torsional T2 and $1^{\text {st }}$ vertical V2 modes is gradually decreasing from 2,94 at $\xi=0$ to 1,73 at $\xi=5,0$ suggesting that footbridge structural torsional stiffness is reducing. On the other hand, it seems that cable stiffness has less influence on torsional modes than on vertical modes. But, with increasing in the cable stiffness the cross section and the weight of cables increases which may result in reducing the frequencies.

\section{The Effect of Material Properties}

Main cable properties that would affect the suspension systems modal behavior are geometry and material properties, such as elastic modulus (E and G) and mass density $(\gamma)$. Due to limited space of present paper, the results of the effect of the first two parameters are not presented here. The effect of these two parameters can be indirectly observed through the dimensionless cable stiffness ratio $\xi$ just described in section 4 of the present paper. In this section only the effect of cable material density on the modal behavior of the footbridge is briefly analysed.

The effect self weight of cable is represented by the relative mass density $\gamma / \gamma_{0}$ where $\gamma_{0}$ is the initial value of mass density used in the current model. The numerical simulations were for ratio $\gamma / \gamma_{0} 0,25 ; 0,50$; 1,$75 ; 1,0 ; 1,25$ approximately covering all practical cases. The variation of the relative frequencies of vertical and torsional modes as a function of dimensionless cable mass parameter $\gamma / \gamma_{0}$ is shown in Fig. 5 .

Firstly, it was found that factor $\gamma / \gamma_{0}$ has very little effect $(1-2 \%)$ on the values of both vertical and torsional natural frequencies of the system with flexible cables. Comparison of natural frequencies of the system with rigid main cables reveals the tendency for increasing frequencies with decreasing of cable mass parameter $\gamma / \gamma_{0}$. The bending and rotational responses are linear. It seems that application sof light-weight FRP cables comparing to traditional materials can be reasonable and advantageous. 


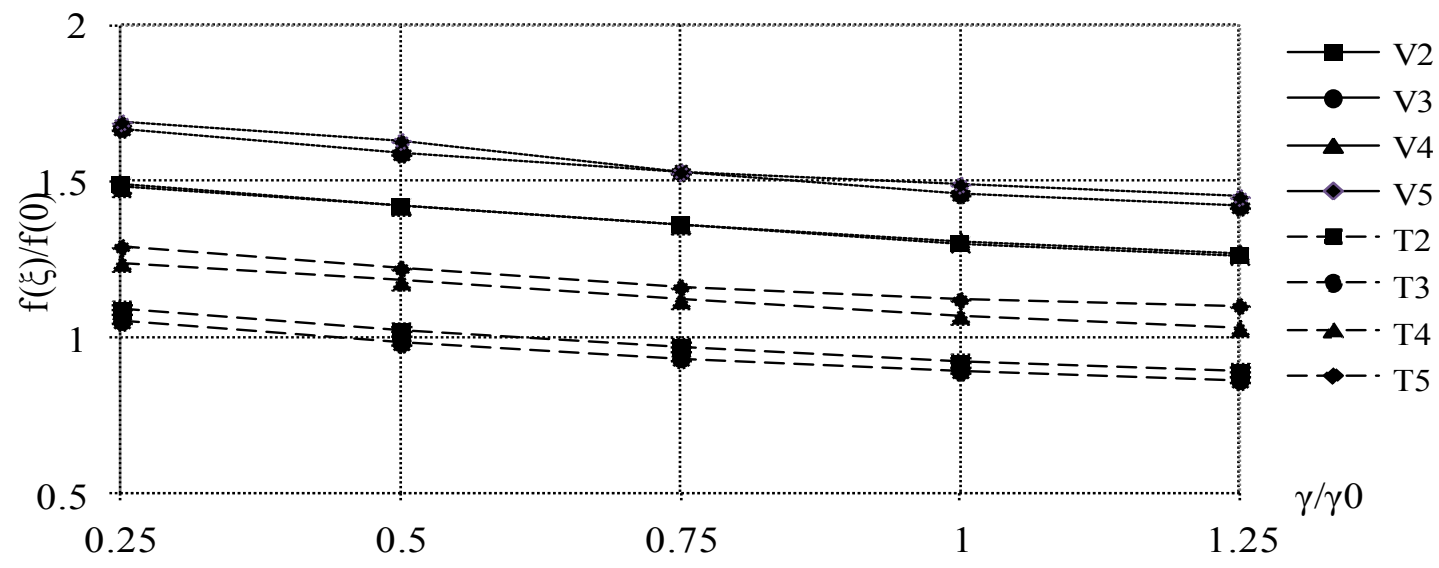

Fig.5 Free Vibration Relative Frequencies as a Function of Cable Mass Ratio $\gamma / \gamma_{0}$

\section{Conclusions}

In this study, a suspension bridge model taken into account varying bending stiffness of cables is proposed to investigate. A single span steel suspension footbridge composed of variable bending stiffness cables and relatively flexible deck as an example of a suspension system was investigated subject to free vibration response.

A three-dimensional finite-element model was used to extract the natural frequencies and obtain their corresponding mode shapes as well as simulating the footbridge response to variation of elastic properties and material densities of bridge cable. Within the frequency range $0-5 \mathrm{~Hz}$ to be important for pedestrian induced excitations the lowest nine vibration modes were identified and analysed.

The numerical simulations show that cable bending stiffness contributes a considerable effect on the natural frequencies of the suspension system, and affects vertical modes more significantly than torsional ones. Increasing the cable bending stiffness, the values of frequencies are also increased by maximum of about $80 \%$ for vertical modes and of about $25 \%$ only for the higher torsional modes. It is also observed that the first lower torsional mode frequencies can slightly decrease when the cable stiffness increases, probably, due to increasing the eccentric mass of the cables and reordering of modes. The higher cable stiffness results in delay of torsional modes and higher vertical modes. Cable mass factor $\gamma / \gamma_{0}$ does not make considerable changes to the values of frequencies of the system with flexible cables. The both vertical and torsional frequencies of the system with rigid cables increase with decreasing in the cable self-weight.

Main cable geometry and material properties, such as modulus of elasticity ( $E$ and $G)$ and density $(\gamma)$ values would affect the flexural (EI) and torsional (GJ) rigidities of the cross sections as well as the modal mass activated in a specific mode of vibration and as a result the various values of the dynamic stiffness of the whole system and its dynamic response should be obtained.

\section{References}

[1]P. A. Irvin, S. Stoyanoff, J. Xie, M. Hunter, Tacoma Narrows 50 years latter - wind engineering investigations for parallel bridges, Bridge structures. 1(1) (2005) 3-17.

[2]M. Barelli, J. White, D. P. Billington, History and aesthetics of the Bronx-Whitestone bridge, Journal of Bridge Engineering. 11(2) (2006) 230-240.

[3]E. T. Ingolfsson, C. T. Georgakis, T. Jonsson, Pedestrian-induced lateral vibrations of footbridges: A literature review. Engineering Structures 45 (2012) 21-52. 
[4]S. Nakamura, T. Kawasaki, Lateral vibration of footbridges by synchronous walking, Journal of Constructional Steel Research. 62(11) (2006) 1148-1160.

[5]L. Bruno, F. Venuti, V. Nasce, Pedestrian-induced torsional vibrations of suspended footbridges: Proposal and evaluation of vibration countermeasures, Engineering Structures. 36 (2012) 228-238.

[6]T. Grigorjeva, A. Juozapaitis, Z. Kamaitis, Static analysis and simplified design of suspension bridges with various rigidity of cables, Journal of Civil Engineering and Management. 16(3) (2010) 363-371.

[7]G. Bartoli, P. D’Asdia, S. Febo, C. Mannini, S. Noè, L. Procino, Innovative configurations for long-span suspension bridges, Proceedings of $5^{\text {th }}$ European and African Conference on Wind Engineering - EACWE 5, Florence, Italy July 19-23. (2009) 12.

[8]L. Bruno, F. Venuti, A. Scotti, Limit of hanger linearity in suspension footbridge dynamics: A new section model, Journal of Sound and Vibration. 330(26) (2011) 6387-6406. 